\title{
RELAÇÕES ENTRE OS REINOS PENINSULARES $(1290-1330)$
}

\author{
Humberto BAQUERO MORENO
}

Universidade de Porto

Parece não haver margem para dúvidas que a política de D. Dinis se insere numa conjuntura que implica um estreito relacionamento com os estados peninsulares: Castela e Aragão. Em conformidade com as principais linhas apontadas pela moderna historiografia portuguesa, a razão principal deve-se sobretudo à circunstância deste reinado, iniciado após a morte do seu progenitor D. Afonso III, ocorrida em 16 de Fevereiro de 1279, se caracterizar por uma acentuada estabilidade interna, resultante duma autoridade régia incontestada, em contraste com o estado geral em que se encontrava o reino de Castela, onde imperava um acentuado clima de ingovernabilidade e de permanentes conflitos sociais'.

Um dos primeiros grandes sucessos da política externa portuguesa consiste na realização do casamento entre o monarca e D. Isabel, filha de Pedro III de Aragão. Tratou-se, com efeito, dum êxito da diplomacia portuguesa, tendo o bom resultado das diligências encetadas pertencido aos procuradores do rei, João Velho, João Martins e Vasco Pires, seus vassalos, a quem coube negociar as cláusulas do matrimónio e simultâneamente receberem a noiva, por palavras de presente, legitimados pela procuração que Ihes havia sido outorgada pelo rei de Portugal em 12 de Novembro de $1280^{2}$.

A missão realizada pelos embaixadores portugueses revestia algum melindre na medida em que a princesa aragonesa era requestada por outros embaixadores dos

1 Sobre esta matéria veja-se a síntese de José MATTOSO in «História de Portugal», vol. II, Lisboa, 1992, pp. 148 e seg.

2 Arquivo Nacional da Torre do Tombo (A.N.T.T.), Chancelaria de D. Dinis, hivro 1, fol. 42. 
reis de França e de Inglaterra, cujo objectivo visava o mesmo desiderato em benefício de seus filhos herdeiros ${ }^{3}$.

Por decisão assumida por Pedro III, foi outorgada em 11 de Fevereiro de 1282 a carta real em que se concretizava o casamento entre D. Dinis e D. Isabel. O monarca português procedia à doação a sua noiva, em arras, de doze castelos e três vilas. Em conformidade com os itinerários sabe-se que D. Dinis se encontrava em Trancoso, em Junho de 1282, vila cuja doação fez a sua mulher no dia 26 desse mesmo ano. As bodas efectuaram-se nessa localidade, onde ambos permaneceram até aos primeiros dias de Agosto 4 .

Aos desígnios políticos de Portugal interessava este matrimónio, não só porque D. Isabel usufruía do maior prestigio pelas suas excelsas qualidades, mas ainda devido ao peso estratégico de Aragão, tanto do ponto de vista político como económico, e dum modo particular ao posterior protagonismo de Jaime II (1291-1327) sobre o espaço do mar Mediterrâneo.

Os anos que se seguem, e sobre os quais não nos iremos deter, caracterizam-se pela guerra civil em Castela, que coloca Afonso o Sábio contra o príncipe D. Sancho. Entre os principais eventos cumpre destacar a embaixada enviada a Castelo por D. Dinis, após Abril de 1284, a dar os pêsames a Sancho IV pelo falecimento de seu pai e a felicitá-lo pela sua elevação ao trono. Um facto, contudo, contribuiu para a irritação do monarca português: a intitulação pelo soberano de Castela de rei do Algarve ${ }^{5}$.

Apesar deste e doutros percalces as relações entre D. Dinis e D. Sancho podemse considerar estáveis, indo ao ponto de ambos se associarem para durante a primavera $\Theta$ o verão de 1289 combaterem o rei aragonês, não se importando o rei de Portugal que o prejudicado era o seu próprio cunhado. A concertação da aliança em curso surgira da entrevista realizada entre ambos os monarcas, no Sabugal, no mês de Dezembro de 1288. As boas relações existentes entre ambos os lados apenas viriam a esmorecer em 1293, quando D. Dinis protege D. João Nunes de Lara na sua contenda com o monarca castelhano, situação que se agrava ainda mais quando este decide casar seu filho, o futuro rei Fernando IV, com a filha de Felipe o Belo, rei da França ${ }^{6}$.

Sancho IV morre em 25 Abril de 1295, implicando o seu falecimento uma acentuada turbulência no reino de Castela. Um pouco antes do seu passamento determinara no seu testamento que se devolvessem com a maior brevidade, ao rei $D$. Dinis, as vilas de Serpa, Moura, Mourão, Aroche e Aracena, as quais haviam sido injustamente arrebatadas a Portugal e se encontravam indevidamente retidas pelos castelhanos?.

Ainda pela mesma altura faz mercê à sua sobrinha infanta $D$. Branca, filha de D. Dinis, de todo o património existente entre Badajoz e Aroche, preocupado o monarca castelhano pelo seu bem estar material. De notar que esta doação foi efectuada

3 Ruy DE PINA, Crónica de D. Dinis, Porto, 1945, cap. II, pp. 11-12.

4 Itinerário del-rei D. Dinis (1279-1325), Lisboa, 1962, p. 17.

5 'VISCONDE DE SANTAREM, Quadro elementar das relações políticas e diplomáticas de Portugal, tomo I, Paris, 1842, p. 113.

6 José MATTOSO, ob. cit., p. 150.

7 VISCONDE DE SANTAREM, ob. cit., pp. 115-116. 
em o dia 24 de Abril, precisamente um dia antes do falecimento do monarca, o qual se encontrava em Toledo gravemente enfermo ${ }^{8}$.

Durante a menoridade de Fernando IV, de Castela, que apenas tinha nove anos, a tutoria de sua mãe D. Maria de Molina, que assumiu as funções de regente desse reino veio a ser contestada pelos infantes D. João, irmão de Sancho IV e D. Henrique, irmão de Afonso o Sábio. Pertenceu a D. João a tarefa de procurar o auxilio do rei português para o que se deslocou à cidade da Guarda com a finalidade de selar um pacto com D. Dinis. Este deve ter-se verificado em finais de Julho, altura em que o monarca se demorou nessa cidade, tendo ficado acordado que o rei português apoiaria as pretensões do infante D. João no seu desiderato de ocupar o trono de Leão, cuja integração com Castela se verificara em $1230 \mathrm{com}$ Fernando III, o Santo ${ }^{9}$.

$\mathrm{Na}$ sequência do mencionado encontro entre D. Dinis e D. João, Portugal declara guerra a Castela, incumbindo os seus embaixadores de a anunciarem junto de Fernando IV. Nas cortes que entretanto se realizavam em Valladolid causou entre os presentes enorme impressão o anúncio do rei português, tanto mais que havia plena consciência das dificuldades que revesteria uma guerra com Portugal. Após a audição dos mensageiros portugueses pertenceu ao infante D. Henrique a iniciativa de se entrevistar com o rei $D$. Dinis. De observar que nessas cortes o referido infante fora designado tutor de seu sobrinho, o rei $\mathrm{D}$. Fernando IV, o que the conferia legitimidade para negociar com o monarca português, evitando um confronto militar ${ }^{10}$.

$\mathrm{Na}$ entrevista celebrada na cidade da Guarda em 6 de Setembro de 1295, D. Henrique era portador duma carta em que se comprometia em nome de Castela, a proceder à devolução de diversas terras que foram sempre pertença de Portugal e que por isso mesmo deviam ser entregues. Constava desse documento de devolução a restituição das vilas de Serpa e Moura, com os seus termos e castelos. Com base na reinvindicação de D. Dinis, comprometia-se D. Henrique a entregar Aroche e Aracena, dando assim cumprimento a uma cláusula contida no testamento de Sancho IV ${ }^{11}$.

Coube ao infante D. João ratificar em 4 de Outubro de 1295, por carta passada desde Ciudad Rodrigo, o convénio que fora estabelecido com o rei português. Assim, em 20 de Outubro o rei D. Dinis recebeu as vilas de Moura e Serpa, o castelo de Noudar, inserido no termo de Moura e ainda o castelo de Mourão. A devolução destas localidades e fortalezas deixava em aberto um problema: a necessidade urgente de delimitar com precisão a linha da fronteira, com o objectivo de incorporar no reino de Portugal muitas terras que devido a uma indefinição da fronteira se consideravam usurpadas. A entrega seria feita ao porteiro da coroa João Rodrigues, que por seu turno as daria ao cavaleiro Nuno Fernandes Cogominho, que assumiria a sua posse em nome do rei D. Dinis ${ }^{12}$.

8 A.N.T.T., Gaveta XVIII, maço 9, no 1. Publicado em As Gavetas da Torre do Tombo, vol. IX, Lisboa, 1971 , pp. 408-410.

9 VISCONDE DE SANTAREM, ob. cit., p. 116.

10 Fortunato DE ALMEIDA, História de Portugal, vol. I, Coimbra, 1922, pp. 242-243.

11 A.N.T.T., Direitos Reais, livro 3, fol. 138.

12 A.N.T.T., Gaveta XIV, maço 4, n 17 Documento publicado em As Gavetas da Torre do Tombo, vol. III, Lisboa, 1963, p. 614. 
Em 20 de Outubro o rei Fernando IV e o infante D. Henrique comprometiam-se por carta, junto de D. Dínis, a entregar-lhe os castelos e vilas de Aroche e Aracena. $O$ prazo de entrega decorria entre 28 de Setembro de 1296 e 28 de Março do ano seguinte ${ }^{13}$.

A proposta em apreço causou a maior irritação no monarca português que via nesta atitude uma manobra dilatória para atrasar a entrega dessas importantes localidades estratégicas. Esta equivocidade teve como consequência que em Janeiro de 1296 se tenha constituído uma liga que visava desmembrar os estados de Fernando IV. Entrava na sua composição o rei de Aragão, Jaime II, e seu irmão o infante D. Pedro, cunhados do rei D. Dinis; D. Afonso de Lacerda, primo de Fernando IV e o infante D. João. Em função do compromísso assumido este último governaria o reino de Leão, Galiza e Asturias, enquanto D. Afonso tomaria conta do trono de Castela e da Andaluzia. A Jaime ll caberia o reino de Murcia. De notar que tanto D. João como D. Afonso chegaram a ser proclamados monarcas ${ }^{14}$.

Nos primórdios do mês de Janeiro de 1296 o infante D. João entra em território português e alia-se com D. Dinis, o qual se mostra disponivel para o auxiliar na conquista do reino de Leão, no qual se auto-proclamara monarca. Dentro da mesma lógica o rei de Portugal entra no pacto celebrado, em 21 de Janeiro, em Bordalva, o qual confederava os acima mencionados castelhanos e aragoneses ${ }^{15}$.

A entrada do exército português deu-se em terras de Castela no mês de Setembro de 1296, actuando D. Dinis como aliado dos infantes D. João e D. Afonso de Lacerda. $O$ rei português "com suas gentes bem ordenadas emtrou em Castella por as comarquas de Cidade Rodrigo e de Ledesma e na frontarja os portugueses tomaram por força hu castello que dizem Torres e mataram todollos contrarios que nelle acharam. $E$ dy foy el Rey Dom Dinis fazendo crua guerra sem algua resistencia nem contradicam quarenta legoas de Castella atee o lugar de Symancas que he duas legoas de Valhadolid honde el Rey dom Fernando estaua. E a tençam de todos era que elRey dom Dinis ho hya çerquar para que repartyam suas estançias de que a hua parte dauam a el Rey dom Dinis e a outra com a gente dAragam e dom Afonso de Lacerda que era com elle e contra el Rey dom Fernando" ${ }^{16}$.

Com a entrada do inverno, o rei $D$. Dinis teve receio que os castelhanos the cortassem a passagem do rio Douro, pelo que de seguida inverteu a marcha e regressou por Medina del Campo a Portugal, apoderando-se da comarca de Riba Côa, que pertencia na altura a Castela ${ }^{17}$.

No âmbito dos acontecimentos o infante D. João, intitulado rei da Galiza e de Leão, outorgou uma carta em 19 de Novembro de 1296, na qual se declarava que tinha

13 A.N.T.T., Gaveta XIV, maço 8, no 24. Publicado em As Gavetas da Torre do Tombo, vol. III, pp. 796-797.

14 José MATTOSO, ob. cit., p. 150.

15 Jerónimo ZURITA, Anales de la Coroa de Aragon, vol. Il, livro 5, cap. 20, Zaragoza, 1977, p. 494.

16 Ruy DE PINA, ob. cit., cap. VIII, p. 44.

17 Fortunato DE ALMEIDA, ob. cit., p. 243. 
recebido de D. Dinis a quantia de $\mathbf{3 1 5 . 0 0 0}$ maravedis leoneses pela compra da cidade e do castelo de Coria ${ }^{18}$.

Com a finalidade de evitar um conflito aberto com Portugal realizam-se em Zamora cortes nas quais se acordou o cumprimento do testamento de Sancho IV no respeitante às terras devolvidas a Portugal, do mesmo modo que se assentou no casamento do primogénito $D$. Afonso com $D$. Beatriz de Castela. As decisões acordadas em Zamora foram de imediato transmitidas a $\mathrm{D}$. Dinis, obstando-se deste modo a que fosse desencadeada uma nova invasão em Castela. Entre as propostas de paz figurava o casamento de Fernando IV de Castela, apenas com onze anos, com D. Constança, filha do rei D. Dinis, com somente sete anos. Outro dos consórcios seria entre o herdeiro do trono português D. Afonso, com sete anos e D. Beatriz, irmã de Fernando IV, que ainda não completara os quatro anos ${ }^{19}$.

Uma carta de Fernando IV de Castela, datada de 28 de Agosto de 1297, propunha ao rei português que se fizesse uma troca entre os castelos e lugares ocupados na sua incursão por terras de Ribacôa. Eram estes os que integravam a irmandade dos sete castelos pertencentes às vilas de Sabugal, Alfaiates, Vilar Maior, Almeida, CasteloBom, Castelo-Rodrigo e Castelo-Melhor. O escambo implicava o reconhecimento de os direitos de Fernando IV sobre diversas vilas e castelos raianos ${ }^{20}$.

Em função de um conjunto de diligências prévias chegou-se à celebração do tratado de Alcañizes em 12 de Setembro de 1297. As cláusulas de convénio estabeleciam os direitos de Portugal à posse dos castelos ocupados em Ribacôa e ainda ao castelo de Monforte. Outros castelos localizados no Alentejo ficariam sob a soberania portuguesa como era o caso de Campomaior, Ouguela, Olivença e São Felix dos Galegos. Acrescentavam-se a estas concessões os castelos de Moura e Serpa, que apesar de terem sido cedidos em 1295, ainda não tinham sido devolvidos. Por seu turno Portugal renunciava à posse dos castelos de Aroche e de Aracena e ainda aos castelos de Valencia de Alcantara, Ferreira e Esparregal, que se encontravam na posse da ordem de Alcantara ${ }^{21}$.

Nesse mesmo dia, em Alcañizes, procedia-se à ratificação do tratado celebrado em Fevereiro, relativamente aos casamentos acordados. Em 15 de Setembro, Fernando IV fez a promessa que o bispo de Badajoz daria outorga à doação que fizera $\mathrm{a} D$. Dinis da via de Campomaior, pelos direitos que esse prelado possuía sobre essa vila ${ }^{22}$.

Efectivamente, em 30 de Outubro de 1297, o rei de Portugal procedeu ao auto de

18 A.N.T.T., Gaveta XIV maço 1, ํㅜ 10. Publicado em As Gavetas da Torre do Tombo, vol. III, p. 587.

19 VISCONDE DE SANTAREM, ob. cit., p. 120.

20 A.N.T.T., Livro de Extras, fol. $188 \mathrm{v}$.

21 A.N.T.T., Gaveta XVIII, maço 9, no 13. Publicado em As Gavetas da Torre do Tombo, vol. IX, Lisboa, 1971, pp. 500-504.

22 A.N.T.T., Gaveta XVIII, maço 10, n² 9. Publicado em As Gavetas da Torre do Tombo, vol. IX, pp. 535-536. 
posse dos lugares de Campomaior e de Ouguela, dando-se assim cabal cumprimento aos acordos estabelecidos entre ambas as partes ${ }^{23}$.

Entretanto, os nobres e homens bons reunidos nas cortes de Valladolid, produziram uma carta em 12 de Maio de 1298, através da qual requeriam o auxílio de D. Dinis para combater o infante $D$. João e os partidários que o apoiavam. $O$ documento em apreço exprimia a ansiedade pela situação de guerra civil que o reino de Castela atravessava ao por-se em causa a autoridade de Fernando IV. Dando sequência ao pedido de auxilio o monarca português dirigiu-se para Castela à frente do seu exército, tendo-se encontrado em Toro com o infante $D$. Henrique, que se mostrava de extrema duplicidade em toda esta conjuntura. $O$ rei de Portugal propôs à rainha-regente $\mathrm{D}$. Maria de Molina, que reconhecesse D. João como rei de Galiza, no que deparou com a sua recusa. Frustrados os seus intentos regressou a Portugal, tendo permanecido no Sabugal durante todo o mês de Agosto e na primeira quinzena de Setembro a aguardar o desenrolar dos acontecimentos em Castela, os quais entretanto não se alteraram ${ }^{24}$.

No decurso do mês de Janeiro de 1300 o rei D. Dinis enviou uma embaixada a Castela com a finalidade de se entrevistar com o rei Fernando IV e D. Maria de Molina. $O$ encontro teve lugar em Palencia, resultando dos contactos estabelecidos a confirmação dos casamentos do rei de Castela com D. Constança e do herdeiro ao trono de Portugal com D. Beatriz ${ }^{25}$.

Dando seguimento ao acordado, D. Dinis dirigiu-se para Ciudad Rodrigo, no mês de Março de 1300, tendo-se entrevistado com os reis de Castela com a finalidade de repartir as despesas na obtenção das bulas que concediam a dispensa de parentesco com o fim de viabilizar os casamentos acordados em Alcañizes. Em conformidade com as diligências efectuadas foram concedidas as bulas necessárias para a efectivação do casamento entre Fernando IV e D. Beatriz, o que veio a acontecer em Janeiro de $1302^{26}$.

No contexto da diplomacia peninsular D. Dinis enviou, em Novembro de 1300, uma embaixada a Jaime II de Aragão, sendo embaixador o conde João Afonso de Albuquerque, o qual tinha por missão encontrar-se em primeiro lugar com a rainha Maria de Molina, precisamente com a finalidade de se conseguir uma aliança entre os monarcas de Castela e Aragão. Em resposta Jaime II enviou como embaixador a Ramon de Monros, o qual era portador de diversas cartas para D. Dinis, em que lhe requeria, que no caso de o monarca português empreendesse uma viagem a Aragão se fizesse acompanhar de sua mulher D. Isabel. Outras cartas do rei de Aragão foram enviadas ao príncipe $D$. Afonso e a outros fidalgos e prelados portugueses ${ }^{27}$.

23 A.N.T.T., Gaveta XVIII, maço 2, nº 9. Publicado em As Gavetas da Torre do Tombo, vol. IX, pp. 410-414.

24 A.N.T.T., Gaveta XVIII, maço 3, n²1. Publicado em As Gavetas da Torre do Tombo, vol. VIII, Lisboa, 1970, pp. 298-299.

25 VISCONDE DE SANTAREM, ob. cit., p. 125.

26 José MATTOSO, ob. cit., p. 152.

27 Jerónimo ZURITA, ob. cit., vol. II, livro 5, cap. 45, pp. 590-591. 
Entretanto, a seguir ao mês de Agosto de 1302, o rei D. Dinis enviou uma embaixada a Castela chefiada pelo conde de Barcelos, com o objectivo de se consumarem as bodas matrimoniais entre Fernando IV e D. Constança, que alcançara a idade própria para a sua concretização, o que aliás veio a acontecer ${ }^{28}$.

A troca de mensagens diplomáticas acentuou-se durante 1303. Jaime II enviou uma embaixada a Portugal constituída por Domingos Garcia de Echauri, Ramon de Monros e João Garcez de Alagon, a qual tinha como missão alcançar uma trégua tripartida entre o monarca de Aragão, D. Dinis e o infante D. Afonso, que pretendia ser rei de Castela. Contudo para impedir que esta aliança se consumasse, Fernando IV enviou a Portugal como seu embaixador ao infante D. João, instando o estreitamento de laços políticos entre os dois reinos em detrimento de Aragão. Como resultado destas diligências efectua-se no mês de Março de 1303, em Badajoz, uma entrevista entre D. Dinis e Fernando IV, da qual resultou que o monarca castelhano concedeu uma avultada soma de dinheiro ao rei de Portugal29.

Este encontro régio que se ficou devendo à oposição do infante $D$. Henrique ao rei de Castela, traduziu-se no empréstimo de um milhão de maravedis ao monarca português, que em troca se comprometia a auxiliar militarmente a Fernando IV ${ }^{30}$.

$A$ influência de $D$. Dinis surge-nos de um modo manifesto na contenda que opunha Castela e Aragão a propósito da disputa que se travava desde 1296 por causa da ocupação, por parte destes, de Murcia e Alicante. Uma embaixada aragonesa chegada a Portugal em Junho de 1303 viabilizou uma trégua entre os três reinos, difícil de conseguir, devido às ambições do infante $\mathrm{D}$. Fernando de Lacerda ao trono castelhano e às mencionadas disputas territoriais. Uma outra embaixada de Jaime II enviada a Portugal fazia saber que existia uma aliança entre Aragão e o referido infante, pelo que não podia haver qualquer paz ou trégua sem o seu consentimento. Prometia, contudo, entrevistar-se com ele para se alcançar a necessária concórdia ${ }^{31}$.

A natureza destas embaixadas com carácter contraditório, conduz Jerónimo Zurita a produzir este saboroso comentário alusivo a Jaime II: - «Y asi andaba el rey en un mismo tiempo entreteniendo a los unos y a los otros para sacar el mejor partido que pudiese ${ }^{32}$.

Com o propósito de atenuar a tensão política, Jaime II, por carta de 21 de Abril de 1304, declara que não irá atacar alguns castelos pertencentes à soberania de Castela, por os mesmos se encontrarem sob a protecção do rei D. Dinis, do bispo de Zaragoza, e de o tio do monarca de Castela, o infante D. João ${ }^{33}$.

Em Julho de 1304 o rei D. Dinis dirige-se através da Guarda à fronteira leonesacastelhana. A comitiva régia integrava à volta de um milhar de fidalgos, destacando-se a presença da rainha $\mathrm{D}$. Isabel, do irmão do rei, o infante $\mathrm{D}$. Afonso, do seu filho ilegí-

28 VISCONDE DE SANTAREM, ob. cit., pp. 126-127.

29 Idem, lbidem, p. 127.

30 José MATTOSO, ob. cit., p. 152.

31 Jerónimo ZURITA, ob. cit., livro 5, cap. 59, vol. II, pp. 642.

32 Idem, Ibidem.

33 A.N.T.T., Chancelaria de D. Dinis, livro 5, fol. 2. 
timo D. Pedro de Barcelos e de Pero Afonso de Albuquerque. Ao chegar D. Dinis à Guarda recebeu a visita de representante do rel Fernando IV, o escrivão da puridade, Diogo Garcia de Toledo, que tinha por incumbência acompanhar o monarca português na sua visita a Castela. Durante a sua digressão por terras castelhanas nunca D. Dinis consentiu que alguém da comitiva se hospedasse nalguma localidade, recorrendo a tendas de campanha e adquirindo por dinheiro as vitualhas necessárias para a manutenção dos acompanhantes e das montadas ${ }^{34}$.

D. Dinis chegou a Roa e entrevistou-se com o seu genro Fernando IV, seguindo na sua companhia para Agreda. Entretanto Jaime II aguardava o rei de Portugal em Torrellas, na fronteira do seu reino entre Agreda e Tarazona. $O$ encontro verificou-se em princípios de Agosto, sendo grande a recepção que o aragonês fez a $D$. Dinis e a sua irmã Santa Isabel. No dia 8 desse mês o rei português conjuntamente com o infante D. João e o bispo de Zaragoza, dom Jimeno de Luna, lavrou a sentença sobre a contenda que dividia os reis de Aragão e Castela acerca da posse de Murcia. Em conformidade com a mesma pertenceriam ao reino de Aragão as localidades de Cartagena, Elche e Alicante, ficando na posse da Castela, Murcia e Molinaseca, além dos seus termos. Fernando IV ratificou em 9 de Agosto na presença de todos a sentença em apreço e prestou homenagem ao rei de Aragão ${ }^{35}$.

Com a presença dos monarcas dos três reinos realizaram-se grandes festas em Tarazona, localidade em que Fernando IV ratificou a cedência que Afonso o Sábio fizera a $D$. Dinis do reino do Algarve. Uma estreita aliança foi celebrada entre os três monarcas, a qual abrangia o rei de Granada que era vassalo de Fernando IV. Concluídas as cerimónias os reis de Castela e de Portugal regressaram juntos, enquanto Jaime II partiu para Zaragoza ${ }^{36}$.

Decorridos alguns anos, em 15 de Fevereiro de 1312, veio a Portugal uma embaixada enviada por Jaime II. Um dos objectivos que a determinou visava a realização do casamento de sua filha Violante del Bar com um infante português. Outra das questões a tratar prendia-se com a restituição a Portugal de Serpa, Moura, Aroche e Aracena, uma antiga questão que se vinha arrastando. Em aberto existia uma queixa de Fernando IV, em que o mesmo recordava que durante a sua menoridade o rei português se apoderara dessas localidades e das terras de Ribacôa, do que se sentia muito prejudicado. Para obviar a esta contenda Jaime Il enviou a seu irmão, dom João de Aragão, para que se encontrasse uma solução. Dom Dinis consentiu nesta arbitragem e colocou os castelos de Castelo Mendo, Sortelha e Segura sob sua tutela. Um dos embaixadores que representou os interesses do rei de Portugal foi Ramon de Cardona, que era cunhado de Jaime II, por se encontrar casado com sua irmã Dona Beatriz ${ }^{37}$.

No meio desta contenda, travada em Agosto de 1312, o rei de Castela invocava os seus direitos à posse dos castelos de Moura e Serpa, dos sete catelos de Ribacôa e

34 Jerónimo ZURITA, ob. cit., vol. II, livro 5, cap. 56, pp. 668-669.

35 Idem, Ibidem, pp. 669-671.

36 Idem, Ibidem, pp. 671-673,

37 Idem, Ibidem, cap. 97, pp. 759-760. 
Monforte, e ainda os castelos de Olivença, Campomaior, San Feliçes de los Gallegos e Ouguela. Alegava que os dois primeiros pertenceram a Castela durante dezassete anos e os últimos mais de cem anos. Na sua resposta, o rei de Portugal declarava que tanto Serpa como Moura eram terras conquistadas pelos seus antecessores aos mouros, até que Afonso o Sábio as conquistou por força a Afonso III, a braços com a guerra civil na sequência da deposição de Sancho II. Também as terras de Ribacôa eram da conquista dos reis de Portugal até à ocupação dos castelhanos. Igualmente considerava que os castelhanos Ihes haviam usurpado Valencia de Alcantara, Herrera, Esparregal e Ayamonte, localidades estas que foram cedidas a Castela por acordo de Fernando IV e D. Dinis. Também este monarca renunciou à posse de Aroche e Aracena por escambo com Olivença, Ouguela, Campomaior e São Felices de los Gallegos ${ }^{38}$.

Lembravam, ainda, os portugueses, que através do acordo matrimonial, a propósito do casamento de D. Afonso III, com a filha de Afonso X, Dona Beatriz, estabeleciase a cláusula que tendo um filho de ambos, sete anos, receberia o reino do Algarve, o que apenas veio a concretizar-se com Fernando IV ${ }^{39}$.

Em 9 de Setembro de 1312 faleceu o rei de Castela. Sua mulher D. Beatriz enviou a seu pai $D$. Dinis a notícia de tão infausto acontecimento, o que interrompia as negociações em curso ${ }^{40}$.

No início do ano seguinte chegou a Portugal uma embaixada de Jaime II, na qual se solicitava a D. Dinis que o infante D. Pedro de Castela fosse nomeado tutor de Afonso $\mathrm{XI}$, que ficara menor por falecimento de Fernando IV. A pretensão visava o propósito de que o jovem rei fosse criado por sua mãe D. Constança. Essa conjuntura apresentava-se complicada face à divisão reinante. Segundo Zurita «los hechos vinieron en tanta discordia y rompimiento que ni los infantes se pudieron concertar ni mucho menos el reino; y unas ciudades y villas tomaron por tutor el infante don Pedro con la reina doña Maria y otros al infante dom Juan con la reina doña Costanza; y asi en lugar de un tutor hubo diversos señores. $Y$ estaba la tierra en grande escandalo y confusion $»^{41}$.

Com a guerra civil de 1319-1325 que opõe D. Dinis a seu filho D. Afonso, Portugal perde influência na cena internacional, a braços com uma grave crise interna. Sintomática é a entrevista do herdeiro ao trono de Portugal com a rainha de Castela, Maria de Molina, em Fuente Grimaldo, em que acordam que esta escreva a D. Dinis, requerendo-Ihe que abandone o trono a favor de seu filho ${ }^{42}$.

Na sequência desse acordo a rainha Maria de Molina escreve com efeito em 1319, ao rei $\mathrm{D}$. Dinis, para que renuncie ao poder. Em resposta o monarca português dirigese a essa senhora regeitando categoricamente a proposta. Do mesmo modo envia à rainha os seus pêsames pelo falecimento dos infantes $D$. Pedro e D. João ${ }^{43}$.

38 Idem, Ibidem, p. 761.

39 VISCONDE DE SANTAREM, ob. cit., p. 137

40 Idem, Ibidem.

41 Jerónimo ZURITA, ob. cit., vol. II, livro 5, cap. 102, pp. 775-776.

42 VISCONDE DE SANTAREM, ob. cit, pp. 138-139.

43 Idem, Ibidem, p. 139. 
Desgostoso o rei $\mathrm{D}$. Dinis com o comportamento rebelde de seu filho, o infante $D$. Afonso, queixou-se em 1321 a Jaime II, o qual para atalhar o mal e alcançar a concordia enviou a Portugal como seu emissário, a seu irmão D. Sancho. Por seu turno o mencionado infante queixou-se de seu pai a seu tio, o rei de Aragão, acusando o progenitor de ser o culpado do clima de dessassossego que se vivia no reino ${ }^{44}$.

D. Dinis faleceu em 7 de Janeiro de 1325. Após a sua morte vieram a Portugal algumas embaixadas a apresentar os pêsames pelo seu desaparecimento. De Castela manifestaram as suas condolências à rainha viúva $\mathrm{D}$. Isabel e ao novo rei $\mathrm{D}$. Afonso IV, que foi felicitado pela sua elevação ao trono ${ }^{45}$.

Penalizado Jaime II com o sucedido enviou desde Valencia um seu emissário, o cavaleiro Lope Alvarez de Espejo, que em seu nome apresentou as suas condolências e efectuou diligências para a reconciliação entre o novo rei e seu irmão, o infante D. Afonso Sanches ${ }^{46}$.

A seguir a Fevereiro de 1325, o rei de Aragão solicitou a seu sobrinho Afonso IV, que the emprestasse dinheiro para a guerra de Cerdenha, conhecedor que seu pai $D$. Dinis deixara um avultado tesouro ${ }^{47}$.

Com toda a probabilidade, ainda neste mesmo ano, o rei D. Afonso IV enviou a Barcelona como seu embaixador a Lopo Fernandes Pacheco. A missão tinha como finalidade tratar do casamento com $D$. Branca, que era noiva prometida do infante português D. Pedro, filho de D. Afonso IV, com D. João, senhor de Biscaía ${ }^{48}$.

No ano de 1326 verifica-se que Afonso XI de Castela efectua diligências no sentido de se casar com Dona Maria, filha de D. Afonso IV, repudiando para o efeito a filha de D. João Manuel que era neta do rei de Aragão. No termo do mês de Novembro do ano em apreço, o rei de Aragão enviou como embaixador a Portugal a D. Ximeno de Tobia, o qual tinha por missão conseguir junto de D. Afonso IV que este escrevesse ao papa para que o mesmo concedesse a dispensa do casamento entre D. Branca e D. João. De igual modo o embaixador aragonês deveria solicitar, em nome do seu monarca e do de Portugal, a ratificação das pazes celebradas entre eles, Fernando IV e o infante D. João. D. Afonso IV recébeu a embaixada aragonesa quando se encontrava em Estremoz, em 22 de Dezembro, ficando acordado guardarem-se as cláusulas do tratado de amizade que existia entre Portugal e Aragão ${ }^{49}$.

Em Setembro de 1327, o rei de Portugal enviou como seu embaixador à corte aragonesa, a Lourenço Gomes de Abreu. O encontro entre o emissário de $D$. Afonso IV e Jaime II deu-se, em 18 de Outubro, deste ano, na cidade de Barcelona. Segundo a carta de crença do representante diplomático referia-se que entre os reis de Portugal e de Castela se tinha concertado o casamento entre a infanta D. Maria, filha do referido monarca com o próprio soberano castelhano, o qual desejava romper o seu

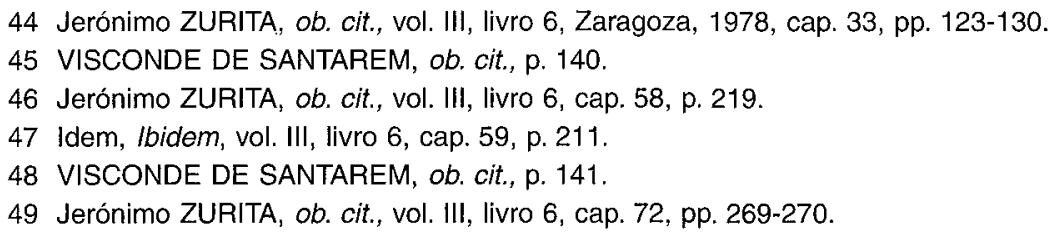


matrimónio com D. Constança, neta do rei aragonês. Usando do maior tacto diplomático D. Afonso IV transmitia ao seu homólogo aragonês que tal acontecimento não visava desconsiderá-lo, antes pelo contrário, requeria o seu conselho e consentimento. Com firmeza Jaime II respondia que Afonso IV dispunha do bom senso necessário para entender que esta atitude constituía uma afronta para si, para seus filhos e para sua neta D. Constança. Atendendo ainda ao vinculo de amizade que existia entre Portugal e Aragão, este facto representava igualmente uma afronta para a coroa portuguesa, pelo que D. Afonso IV deveria rejeitar categoricamente «tan flacas y coloradas razones las que el rey de Castilla daba para fundar y justificar el divorcion ${ }^{50}$.

Partiu para Portugal, em Outubro de 1327, o embaixador Boshom Ximenez com a finalidade de evitar o desenlace previsto. A missão traduziusse num insucesso, dado que o rei de Castela estava determinado a repudiar sua mulher. A guerra civil estava desencadeada com a oposição de D. João Manuel, que com a sua hoste combateu o rei de Castela ${ }^{51}$.

No decurso deste mesmo ano o rei castelhano enviou uma missão secreta a Portugal para se inteirar da sensibilidade do monarca português acerca do casamento do próprio soberano de Castela com D. Maria e simultâneamente o divórcio com D. Constança. A reacção de Afonso IV foi muito negativa ao insurgir-se contra o siligismo de que se revestia essa missão, do mesmo modo que defendia que a primeira tarefa a encetar consistia na publicação do divórcio ${ }^{52}$.

Apostado no estreitamento das boas relações com Portugal, Afonso XI, em 18 de Outubro de 1327, passou uma procuração a Pero Ruiz de Villegas e a Fernão Fernandez de Pina, para que com toda a minúcia passassem em revista e ratificassem os acordos celebrados entre os monarcas de Castela e de Portugal, Fernando IV e D. Diniz, respectivamente ${ }^{53}$.

No mesmo dia da procuração o rei de Castela outorgou outra carta aos mesmos procuradores, concedendo-thes poderes para que pudessem receber por palavras de presente a infante D. Maria, filha do monarca português ${ }^{54}$.

Provávelmente, em Novembro de 1327, nova embaixada de Castela foi enviada por Afonso XI ao rei de Portugal. A proposta visava o casamento do herdeiro do trono português, D. Pedro, com a infanta de Castela D. Branca, impedindo, deste modo, a possibilidade de qualquer aliança entre Portugal e o seu adversário, o infante $D$. João Manuel. Esta iniciativa deparou com uma recusa de D. Afonso IV, que diferiu a proposta para um encontro pessoal a realizar entre ele e o rei de Castela ${ }^{55}$.

Enquanto se desenvolvia intenso intercâmbio diplomático entre os mencionados reinos de Portugal e Castela falecia em Barcelona, após prolongada doença, no dia 2

50 Idem, Ibidem, vol. III, livro 6, cap. 73, pp. 275-276.

51 Idem, Ibidem.

52 VISCONDE DE SANTAREM, ob. cit, pp. 145-146.

53 A.N.T.T., Gaveta XVIII, maço 11, nº 5. Publicado em As Gavetas da Torre do Tombo, vol. IX, pp. 636-657.

54 A.N.T.T., Casa da Coroa, gaveta 17, maço 1.

55 VISCONDE DE SANTAREM, ob. cit., p. 147. 
de Novembro de 1327, o rei de Aragão, Jaime II, com a idade de sessenta e seis anos $^{56}$.

Em 17 de Dezembro de 1327, efectuou-se em Coimbra a celebração de um tratado de paz e amizade entre Afonso XI e Afonso IV, em que se procedia à ratificação de todos os convénios acordados pelos seus progenitores D. Dinis e Fernando IV ${ }^{57}$.

Decorridos alguns dias, em 26 de Dezembro, realiza-se na mesma cidade o tratado de casamento entre D. Maria, filha do rei de Portugal e Afonso XI de Castela ${ }^{58}$.

No ano seguinte, no lugar de Alfaiates deu-se um encontro entre Afonso IV e Afonso $\mathrm{XI}$, tendo-se celebrado as bodas do rei de Castela com a infanta D. Maria de Portugal. Logo de seguida, em Fuente Aguinaldo, efectua-se o casamento entre D. Pedro, herdeiro de Portugal e D. Branca, filha do infante D. Pedro de Castela ${ }^{59}$.

Durante a permanência em Fuente Aguinaldo dos reis de Portugal e de Castela, o primeiro aconselha o segundo que se alie com o novo monarca de Aragão, Afonso IV, para assim deixar isolado a $D$. João Manuel e impedir uma aliança com o aragonês. Para 0 atrair deveria propor-Ihe o casamento com sua irmã $D$. Leonor e de imediato mandar restituir D. Constança a seu pai o infante D. João Manuel ${ }^{60}$.

Tomando a iniciativa os reis de Portugal e de Castela procuram confederar-se com Afonso IV de Aragão, ratificando os acordos anteriores, e levando se possível este monarca a marginalizar ao infante $D$. João Manuel. Essa tentativa não resultou na medida em que o aragonês invocava que antes de mais nada era indispensável a reconciliação entre Afonso XI e o referido infante ${ }^{61}$.

Num esforço de aproximação, Afonso IV de Aragão, por procuração de 25 de Agosto de 1328, designou o membro do seu conselho, Gonçalo Garcia, para que em sua representação alcançasse o acordo de ratificação do tratado de amizade entre os três reinos, Aragão, Castela e Portugal, que tinha sido celebrado em Agreda a 9 de Agosto de 1304. Tal desiderato veio a ser conseguido entre as três partes, em Medina del Campo, em 21 de Outubro de 1328. A ratificação de Afonso IV de Aragão deu-se em 31 de Janeiro de $1329^{62}$.

Fruto desta série de esforços diplomáticos traduziu-se em Agreda, em 5 de Fevereiro de 1329, na efectivação de um tratado de liga entre os monarcas dos três reinos, em cujas cláusulas se estabeleceu um pacto de amizade, mediante o qual se declarou que seriam amigos dos seus amigos e inimigos dos seus inimigos, não consentindo a permanência em seus reinos de adversários mútuos e conjugando esforços no sentido concertar esforços para combater os muçulmanos. Ainda em conformidade com o tratado de paz acordava-se que $\mathrm{D}$. Branca de Castela seria entregue à rainha de Por-

56 Jerónimo ZURITA, ob. cit., vol. III, livro 6, cap. 75, p. 282.

57 VISCONDE DE SANTAREM, ob. cit.

58 A.N.T.T., Casa da Coroa, gaveta 17, maço 1, p. 147.

59 VISCONDE DE SANTAREM, ob. cit., p. 149.

60 Idem, Ibidem, p. 150.

61 Jerónimo ZURITA, ob. cit,, vol. III, livro 6, cap. 79, p. 295.

62 A.N.T.T., Gaveta XVIII, maço 5 n 32. Publicado em As Gavetas da Torre do Tombo, vol. VIII, pp. 566-575. 
tugal, D. Beatriz, até alcançar os doze anos, idade que lhe permitiria contrair casamento com o herdeiro da coroa D. Pedro ${ }^{63}$.

A amizade entre Portugal e Aragão viria a ser selada em 2 de Novembro de 1329 através do representante diplomático de Afonso IV, Lopo Fernandes Pacheco e o rei Afonso IV de Aragão, com a ratificação em Valencia do tratado de Agreda de 9 de Agosto de 1304, uma pedra decisiva que viria a consolidar toda a estratégia política concertada pelos reis D. Dinis, Fernando IV e Jaime $11^{64}$.

Com a ratificação assinalada assiste-se ao coroamento duma política que veio reforçar os laços existentes entre os três reinos, pese embora as vicissitudes entretanto vividas, o que significa que para além das constantes relações entre Portugal e Castela, as mesmas estendiam-se ao reino de Aragão, certamente incrementadas pela constante influência da rainha Santa Isabel, aragonesa, que viveu em Portugal entre 1282 e 1336, mantendo um papel fundamental no estreitamento de contactos entre o espaço atlântico e mediterrânico, tanto no plano afectivo como político.

63 Jerónimo ZURITA, ob. cit., vol. III, livro 7, cap. 7, pp. 321-323.

64 Idem, Ibidem, vol. III, livro 7, cap. 9, p. 329. 